\title{
CIRCULACIÓN DE INTELECTUALES ALEMANES EN CHILE Y CHILENOS EN ALEMANIA (FINES DEL SIGLO XIX Y COMIENZOS DEL SIGLO XX)*
}

\author{
Circulation of German Intellectuals in \\ Chile and Chilean Intellectuals in Germany \\ (turn of the $20^{\text {th }}$ century)
}

Carlos Sanhueza*

\begin{abstract}
RESUMO
Esse artigo analisa a influência dos intelectuais alemães no Chile, por volta da virada do século XX. Naquela época, a Alemanha era um modelo científico e militar de educação para o resto do mundo e nós abordamos aqui a maneira como o Chile tentou adotar esse modelo. Primeiro, trata-se de mostrar como a circulação de conhecimentos, práticas e intelectuais ocorreu entre os dois países. Em segundo lugar, esse artigo discute como o interesse demonstrado por alguns intelectuais chilenos pela Alemanha criou uma série de controvérsias e discussões sobre o lugar ocupado pelo Chile no cenário civilizatório europeu. A esse respeito, as controvérsias sobre o dito embrujamiento alemán são analisadas como um conjunto de questões sobre o valor da cultura germânica em um país com raízes latinas.

Palavras-chave: transferências de conhecimento; intelectuais chilenos na Alemanha; intelectuais alemães no Chile.
\end{abstract}

\footnotetext{
ABSTRACT

This paper analyzes the influence of German intellectuals in Chile around the turn of the 20th Century. At that time, Germany was a scientific and military educational model for the rest of the world, and

Este artículo forma parte de un proyecto de investigación FONDECYT-Regular No 1100550 referido a la circulación de conocimiento entre Chile y Alemania entre 1870 y 1914. El autor agradece a la Comisión Nacional de Investigación Científica y Tecnológica de Chile (CONICYT) el apoyo prestado.

** Profesor de la Universidad de Talca-Chile.
} 
we discuss here how Chile tried to adopt this model. First, this paper deals with how the circulation of knowledge, practices and intellectuals took place between the two countries. Second, this article discusses how the interest shown by some Chilean intellectuals in Germany created a series of disputes and discussions about Europe's civilizing role in Chile. In this respect, the controversies of the embrujamiento alemán are analyzed, as a set of questions about the value of Germanic cultures in a country with Latin roots.

Key-words: knowledge transfer; Chilean intellectuals in Germany; German intellectuals in Chile.

\section{El problema}

La relación entre Chile y Alemania durante los últimos decenios del siglo XIX se ha enfocado desde diferentes perspectivas. En un sentido, los estudios sobre migraciones de alemanes a Chile ha dominado el análisis de los intercambios entre ambos países. Si bien tales trabajos ponen énfasis en la primera mitad del siglo XIX, muchos proyectan la mirada hasta el fin del siglo XIX (BLANCPAIN, 1987; KREBS, 2001). Por otro lado, los estudios respecto de las relaciones militares entre Chile y Alemania han sido de gran importancia. Se ha visto el papel de los consejeros alemanes en Chile (RINKE, 2004b), así como la expansión alemana indirecta desde Chile hacia Sudamérica y las características militares prusianas aplicadas en Chile (FISCHER, 1999). Finalmente, se ha señalado la presencia germana en la conformación de la educación nacional (NORAMBUENA, 2003). Otros han destacado la participación de científicos alemanes durante el período, sin llegar a analizarlos en un nivel monográfico, ni de investigación documental (CARRASCO, 2002).

Lo que aquí se busca es, a partir de los enfoques antes citados, analizar los elementos que de alguna forma enlazaron las diferentes presencias de los alemanes y de Alemania en Chile por fines del siglo XIX. Su objetivo no es sólo estudiar el papel desempeñado por los germanos en Chile, sino además poder observar en qué medida lo acontecido en Alemania tuvo una repercusión en la historia chilena. 
Lo anterior se analiza desde dos entradas. Por un lado, se estudia cómo se produjo la circulación de saberes, prácticas e intelectuales entre ambos países. En segundo lugar, se estudia en qué sentido el interés mostrado por ciertos intelectuales chilenos por Alemania generó un conjunto de controversias y discusiones (el llamado Embrujamiento alemán) sobre el lugar que Chile ocupaba dentro del escenario civilizador europeo.

\section{Introducción}

La presencia alemana en Chile se advierte desde centurias previas al siglo XIX (PIETSCHMANN, 2005). Sin embargo, será en el período decimonónico en donde la huella germana se haga sentir.

En primer lugar, la figura de Alejandro de Humboldt influyó en la intelectualidad chilena del siglo XIX. Si bien Humboldt no estuvo en los límites de lo que hoy conocemos con el nombre de Chile, de alguna manera arribó al país. Por un lado, las proyecciones de la ciencia humboldtiana se observan nítidamente en los viajeros científicos que realizaron un periplo por Chile, como en el naturalista Eduard Poeppig. Este último utilizó el esquema humboldtiano de los cuadros de la naturaleza, vinculando sus investigaciones sobre la botánica chilena, con su población y costumbres (SANHUEZA, 2006a). La influencia de Alejandro de Humboldt, en otro sentido, se advierte en el desarrollo mismo de la actividad científica en Chile. A pesar de que la gravitación del naturalista prusiano en Chile no es notoria, en comparación a los países en que éste sí estuvo, la obra del viajero alemán no pasó desapercibida entre los primeros científicos extranjeros radicados en Chile. Lo anterior, no tan sólo por la figura de Humboldt, punto de partida en Claudio Gay (GAY, 1845), sino también en la medida en que llegó a ser un modelo de trabajo de campo y exposición de resultados, como en Rudolf Amandus Philippi (SANHUEZA, 2010a). Finalmente, Alejandro de Humboldt llegó a constituir un campo de legitimación para la propia intelectualidad chilena del siglo XIX. Desde esta perspectiva el nombre del autor berlinés fue invocado por Andrés Bello (JACKSIC, 2001), quien lo difundió en Chile, así como por intelectuales como Benjamín Vicuña Ma- 
ckenna. Este último, según lo declaró en su diario de viajes, incluso llegó a visitar al naturalista germano en la ciudad alemana de Potsdam (NÚÑEZ, 1988; SANHUEZA, 2006a).

En segundo lugar, la inmigración alemana a Chile sin duda marcó un hito en las relaciones entre ambos países. Desde 1840 se advierte un impulso en las esferas de gobierno a fin de instalar colonias germanas en la zona sur del país, región que estaba en evidente atraso respecto del resto (PÉREZ ROSALES, 1852). En este sentido, la figura de los hermanos Bernhard Eunom y Rudolf Amandus Philippi resultó clave en el establecimiento de colonias en la zona de Valdivia y Llanquihue (BLANCPAIN, 1974 y 1987).

Interesante resulta observar en qué medida la presencia de los inmigrantes alemanes en Chile, a pesar de su número reducido y de su lejanía con los centros urbanos más importantes, fue construyendo una imagen de Alemania y la alemanidad que tendrá una influencia sobre el resto de la población. Dicha imagen previa a la unificación política del país germano, reunía dos elementos que a todas luces valoraba la llegada de tales colonos a Chile: en un sentido estos últimos se percibían como "sobrios, trabajadores y amantes del hogar" (BLANCPAIN, 1987), así como un pueblo que, a decir de Benjamín Vicuña Mackenna, era el menos peligroso para la unidad nacional al venir de un país dividido (VICUÑA MACKENNA, 1855).

Resulta notable advertir cómo la percepción de una Alemania dividida, que apelaba a la falta de un estado unificado, justamente era lo que impedía tomar a los Reinos Germánicos como un modelo a implementar en Chile. El propio Vicuña Mackenna, en su periplo por mediados de siglo XIX por Alemania, le fustiga el estar "presa entre 36 soberanos" (VICUÑA MACKENNA, 1856). En un período en el cual las antiguas colonias hispanas en América habían pasado por constituir nuevos países a pesar de las diferencias y de los conflictos de grupos, la visión de un país sin un Estado unificado, necesariamente colocaba a Alemania en un segundo plano respecto de otras naciones como Francia o Inglaterra (SANHUEZA, 2010a). A partir del reinado de Federico II cambiarán notablemente estas percepciones, juicios y nociones en torno a los reinos germánicos. En efecto, con la unificación alemana, la imagen del país germano se alteró radicalmente (BLANCPAIN, 1987). 


\section{Chile y Alemania: un vínculo finisecular}

Se ha afirmado que ya desde siglo XVIII se habían desarrollado en ciertos Reinos Germánicos, como en Prusia, un conjunto de prácticas orientadas a una administración sobre la base de disciplinas científicas. Lo anterior dejaba en evidencia la importancia que adquiría en Alemania el estudio de la ciencia (BRUCH, 1989; LIDENFELDT, 1997). Sin embargo, será recién con el advenimiento de Federico II al poder en Prusia cuando esta relación saber-poder llegue a ser una marca de identidad del país que se estaba fundando (STRAUB, 2008). El gobernante prusiano consolidó el proceso de modernización que ya sus antecesores habían iniciado. A partir de lo anterior, Alemania se transformó en un modelo de nación al hacer uso de un saber científico en el engrandecimiento de su producción, el perfeccionamiento de su educación, como de su formación militar (RÖHL, 2002). Los triunfos militares obtenidos desde la década de 1870 no habían hecho nada más que reforzar la percepción de una nación que se alzaba por sobre sus vecinos, dejando a Francia (tradicional punto de referencia para Chile) en un segundo plano (RINKE, 2004a). En este sentido, la llamada Política Mundial (Weltpolitik) llevada a cabo por el Imperio Alemán, tradicionalmente vista como la expresión de una búsqueda de hegemonía mundial, vino a ser el correlato internacional de la imagen que dicha nación había forjado. De allí que no resulte extraño el incremento del intercambio de científicos, técnicos y consejeros alemanes hacia aquellos estados inmersos en proceso de modernización (RINKE, 2004a).

Coincidentemente con la emergencia de Alemania como un poder europeo, Chile se alzaba tras la Guerra del Pacífico librada contra Perú y Bolivia (1879-1884) como un país en búsqueda de nuevos modelos de desarrollo. Si bien Francia era indiscutiblemente la senda a seguir, de allí la presencia de científicos, ingenieros y artistas franceses en Chile (VICUÑA, 2001), poco a poco el modelo anglosajón y germano habían entrado a disputar la supremacía gala, hasta ahora dominante (RINKE, 2004b). Los registros de los censos desde 1865 mostraban que los ingenieros alemanes habían desplazado a los franceses, ubicándose en segundo lugar tras los británicos ${ }^{1}$. En el plano militar la relación con Prusia se estrechaba al punto

1 Agradezco esta información a Jaime Parada. 
que el consejero militar Emil Körner, tras fundar la Academia de Guerra, llegaba a los más altos puestos de la jerarquía castrense (RINKE, 2004a). En la esfera del sistema educativo se funda el Instituto Pedagógico en 1890, tras un proceso de estudio y reclutamiento de profesores en Berlín promovido y realizado por Valentín Letelier (NORAMBUENA, 2003; SANHUEZA, 2006b). En las sociedades científicas (como la Sociedad Científica Alemana de Santiago); en los museos (como el Museo de Historia Natural); en la enseñanza universitaria; en el observatorio astronómico etc. la presencia de alemanes tras concluir el siglo XIX y comenzar el XX, se hacía notoria (KREBS, 2001).

¿Cuáles fueron las instituciones que la posibilitaron? ¿Qué saberes fueron a buscar los chilenos en tierra germanas? ¿Qué imágenes de ambos países estuvieron detrás de estos intercambios? ¿Qué roces y conflictos supuso tales transferencias?

\section{A. ALEMANES EN CHILE Y CHILENOS EN ALEMANIA: UN CONJUNTO DE SABERES EN MOVIMIENTO}

Tal y como se ha mencionado, la presencia intelectual de Alemania en Chile desde fines del siglo XIX estuvo marcada por los acontecimientos ocurridos en la propia Europa. En efecto, la imagen que el Imperio Alemán proyectaba en el mundo no sólo se explicaba por su preponderancia militar tras los triunfos obtenidos desde la década de 1870, sino también en la esfera intelectual. Ya desde mucho antes Alemania había desarrollado una relación entre administración y ciencia; poder y saber, que la había distinguido del resto de sus vecinos. Con la creación del Imperio Alemán, y la unificación bajo el mandato de Federico II, lo anterior se había acrecentado. Se ha visto que ya desde 1848 las asociaciones científicas habían cambiado el panorama intelectual de Alemania. Sólo entre esa fecha y 1870 fueron fundadas más de ocho, lo que se unía a la creación de museos en diferentes esferas del saber (geología, mineralogía, etnología etc.), como de la existencia de revistas cada vez más especializadas (PENNY, 2002; RAINA, 2007). Este conjunto de elementos no sólo habían puesto a Alemania en un lugar pre- 
ponderante en el ámbito científico mundial, sino que además había llegado a ser un factor de expansión (en este caso intelectual) hacía lugares lejanos (OYENSE, 1982).

Interesante resulta advertir, en este cuadro de emergencia de Alemania, la decisión tomada por Chile en pos de acercarse al país germano. ¿Qué espacios del saber se privilegiaron? ¿Cómo justificaban este vuelco hacia Alemania?

Alemania se yergue en tanto modelo educativo para Chile. Hacia la década de 1880 las enormes posibilidades que brindaba la exportación del salitre influyó para que los gobiernos de Domingo Santa María y de José Manuel Balmaceda se preocupasen de incentivar mejoras en la educación nacional. Chile entonces no contaba con una institución de educación superior encargada de formar a los profesores secundarios. Si bien existía una experiencia de formación de docentes primarios, impulsada por Sarmiento desde 1843 al fundarse la primera Escuela Normal, la preparación de profesores secundarios no estaba sistematizada. E incluso, muchos de los que desempeñaban dichas funciones lo hacían desde la experiencia y los conocimientos adquiridos en sus profesiones u actividades específicas, sin contar con una preparación pedagógica adecuada. Fue justamente la constatación de esta carencia, lo que llevó al gobierno del presidente Santa María, a enviar una misión pedagógica a Berlín, integrada por Valentín Letelier, Claudio Matte y José Abelardo Núñez, con el objeto de recabar información respecto de los adelantos pedagógicos que se venían suscitando en dicho país. En este entendido, el Ministro Plenipotenciario de Chile en Berlín, Domingo Gana recibió instrucciones a fin de buscar y contratar profesores alemanes con el propósito de instalar en Chile un Instituto Pedagógico Secundario (KREBS, 2001; POZO, 2005).

Sin duda, el vínculo chileno alemán por fines del siglo XIX estuvo muy marcado por la figura de Valentín Letelier (1852-1919). En 1881 su designación como secretario de la embajada chilena en Berlín le permitió investigar el modelo de educación pública prusiano. Este trabajo lo llevó a escribir una memoria para el Ministerio de Instrucción Pública: La instrucción secundaria y la instrucción universitaria en Berlín: informe elevado al Supremo Gobierno por la legación de Chile en Berlín (1885). Además, participó en la tarea de fomentar y dirigir la emigración europea hacia nuestro país, para lo cual escribió un texto que buscaba hacer conocido el país titu- 
lado Chile en 1883. La estadía germana le posibilitó estudiar directamente la educación preescolar, la escuela primaria, la disciplina escolar, los contenidos de la enseñanza prusiana y la instrucción secundaria y universitaria.

Ahora bien, resulta notorio que el estudio de Letelier fue más allá de una mera apropiación de un saber pedagógico.

En primer lugar, este interés por el saber pedagógico germano revelaba la imagen que se poseía de Alemania. Letelier en su informe al gobierno hace hincapié en que medida Chile ha tomado "de segunda mano" la modernización de los sistemas europeos (como el francés), sin estudiar directamente a Alemania, país inspirador de muchos sistemas utilizados en el Viejo Mundo (LETELIER, 1885). Alemania, en la perspectiva de Letelier, había desarrollado una ciencia pedagógica

con una paciencia infinita, haciendo mil ensayos, tanteando mil procedimientos, aprovechando la más mínima observación de la práctica diaria, hasta llegar [...] a cambiar la índole metafísica que se le juzgaba característica del intelecto germano [...], sustituyendo la vía deductiva por la inductiva, y a establecer los principios teóricos de la enseñanza racional (LETELIER, 1940).

La llamada índole metafísica del intelecto germano había sido un tópico común en ciertos intelectuales chilenos respecto de Alemania durante el siglo XIX: un país enclaustrado en su intelectualismo, sin lograr ir más allá de sus cavilaciones (SANHUEZA, 2006a y 2009b). Letelier advierte que ello había sido transformado radicalmente en las postrimerías de la centuria decimonónica, lo que no sólo había significado que el país germano pasase de la teoría del estado (como en Hegel) a la formación de uno (bajo Federico II), sino que también a una aplicación práctica de lo que desde hace muchas centurias tan sólo había sido objeto de reflexiones.

En segundo lugar, los alcances mismos de la reforma pedagógica iban más allá del mero ámbito formativo. En efecto, en una época en donde la secularización de la sociedad chilena era objeto de profundos debates, Letelier ve en la formación pedagógica alemana una "reversión en contra de la educación clerical y a favor de la educación nacional" (LETELIER, 1940). El racionalismo asociado con Alemania, su inclinación por la ciencia, podían ser un freno a "las influencias reaccionarias" de la sociedad chilena, 
como de la "teocracia [...] que nos ha tenido enclaustrados" (LETELIER, 1940). La influencia alemana podría ayudar a romper tal encierro. En este punto, la transferencia del saber pedagógico se instalaba en la esfera política.

Interesante es analizar en qué medida Valentín Letelier no sólo hizo circular el conocimiento pedagógico que recogía en Alemania a esferas políticas, sino también al ámbito militar y científico. Si se observan las cartas que desde Berlín envió Letelier, se advierte cómo éste enlazó el sistema educativo con la enseñanza militar y la organización de la ciencia y la tecnología.

En un sentido, Alemania le ofreció a Letelier un punto de comparación en pos de evaluar el nivel de desarrollo y la enseñanza de la ciencia en Chile. Ignacio Domeyko, quien destacaba en la investigación y la docencia científica, se veía frente a los científicos alemanes como un aficionado, puesto "que no conoce ni los elementos de las ciencias químicas, geológicas y aún mineralógicas" (SANHUEZA, 2006b). Lo anterior no sólo era un simple impresión personal: "algunos alumnos suyos muy distinguidos que han venido en diferentes épocas a estudiar en Alemania, se han visto precisados a renovar todos los estudios hechos porque de las ciencias profesadas por el sabio Domeyko apenas sabían algo más que el nombre" (SANHUEZA, 2006b). Sin duda, la llegada del contingente alemán podía tener una influencia no sólo en los profesores que se formarían con ellos, sino también en renovación de la práctica científica.

Por otro lado, Letelier hace referencia en sus misivas desde Berlín al mentado tópico de que la supremacía militar prusiana se basaba tan sólo en su fuerza bruta. Al respecto, Letelier busca analizar en qué sentido el propio desarrollo del pensamiento germano era la base de su éxito militar:

Los franceses han hecho creer en todo el mundo que ellos, representantes de la inteligencia, han sido vencidos por la fuerza bruta; pero justamente en Alemania es donde se ve que mayor es el predominio del espíritu, porque aún los ascensos no se confieren sino a los más estudiosos y entendidos. La Academia Militar (que no se debe confundir con la Escuela) está especialmente destinada a los oficiales, los cuales siguen estudiando allí hasta viejos. Toda la carrera militar del oficial alemán se descompone en una serie de exámenes sumamente estrictos y se reduce a un continuo certamen... (SANHUEZA, 2006b). 
Para Letelier, la formación militar en Chile, siguiendo el modelo germano, debía basarse en "las ciencias técnicas que atañen al ramo"; construir "las bases de un sistema jerárquico fundado a la vez en la antigüedad y en el saber"; así como lograr "que nuestros oficiales se dediquen a estudiar nuestro territorio, nuestras fronteras, nuestros recursos, nuestros medios de transporte" (SANHUEZA, 2006b). Educación, formación pedagógica y ciencia se unían en Alemania. Para Letelier una esfera del conocimiento no podía separarse de la otra.

Particularmente importante resulta no tan sólo cómo los chilenos buscaron apropiarse y transferir el conocimiento alemán, sino además en qué medida los germanos arribados a Chile lo instalaron y lo trasladaron entre las diferentes esferas del saber.

En esta praxis de transferencias destacaron particularmente Rudolf Lenz (1863-1938) y Hans Steffen (1865-1936), miembros del grupo de profesores alemanes llegados a Chile para trabajar en el recién creado Instituto Pedagógico.

Lenz no sólo ejerció una labor docente en el Instituto Pedagógico, sino también como investigador. En efecto, Lenz hizo del español hablado chileno su objeto de estudio, analizando en qué medida éste poseía fuertes influencias de las lenguas aborígenes, como el mapuche. Junto a lo anterior, Lenz fue un estudioso de la propia lengua mapuche, llegando a realizar una investigación filológica sobre dicho idioma, como de sus variaciones dialectales.

Los trabajos sobre el español chileno le permitieron a Lenz adquirir una comprensión más profunda del país. Lenz critica las formas de enseñanza de la lengua en Chile a partir de los textos de estudio, en la medida en que "se memoriza palabra por palabra", tanto así que lo que no está en el texto pierde importancia a los ojos de lo profesores y de los alumnos (LENZ, 1893, traducción nuestra). Lo anterior, resulta de importancia puesto que va revelando no sólo la estructura de la enseñanza chilena, sino además la percepción de su idiosincrasia. De allí que Lenz vincule ambas esferas al concluir que la propia estructura de control estatal chileno influía sobre las formas de aprendizaje. Tales consideraciones respecto de Chile (muchas veces en la perspectiva comparada con Alemania), serán muy influyentes en la elaboración del un plan de estudios para la enseñanza secundaria chilena que el mismo Lenz ayudó a redactar (ver también Wilhelm Mann, 1910). 
Hans Steffen, al igual que Lenz, fue más allá de sus ocupaciones pedagógicas. Originalmente el trabajo de Steffen se circunscribía a la docencia de historia y geografía en el mencionado Instituto Pedagógico. Sin embargo, pronto se hará notar en otros ámbitos: como geógrafo, expedicionario de la Patagonia Occidental, así como asesor para el gobierno chileno en el Arbitraje con Argentina entre 1898 y 1902. Los biógrafos han enfatizado estas últimas facetas de Steffen (CARRASCO, 2002; POZO, 2005). Sin embargo, poco se ha destacado en qué medida en Steffen confluyeron sus diferentes labores, movilizando un conjunto de saberes y prácticas entre Chile y Alemania.

Particularmente relevante para la investigación de Hans Steffen en una perspectiva de transferencias de saberes, lo constituyen, junto a sus escritos sobre Chile, sus legados depositados en la biblioteca del Instituto Iberoamericano de la ciudad de Berlín-Alemania.

El examen del legado de Steffen revela cómo éste instalaba la historia en sus clases del Instituto Pedagógico. De esta forma no sólo hace un repaso de la Historia Universal, sino que además vincula la historia chilena con la alemana. En sus apuntes se evidencia el papel que le otorgaba a Prusia en tanto ésta se ha transformado en "una gran potencia en Europa", haciendo un símil con la posición de Chile en el contexto de América del Sur (Legado Hans Steffen Inst. Ibero. Berlín, Vortragsmanuskripte B-4). En sus apuntes de clases de geografía, no sólo atendió a las características físicas de los continentes y países, sino que también realizó reflexiones respecto de la relación entre geografía y nivel de desarrollo de los pueblos (Legado Hans Steffen Inst. Ibero. Berlín, Vortragsmanuskripte B-6).

Sin lugar a dudas, la presencia alemana en la esfera militar ha sido uno de los temas más tratados en las relaciones chileno-germanas por fines del siglo XIX. Se ha visto el ethos militar prusiano actuando en Chile, en tanto representó una vía hacia la modernización del ejército chileno tras la Guerra del Pacífico (RINKE, 2004a). Se ha estudiado, por otro lado, la propia participación de la marina prusiana en los acontecimientos bélicos de la Guerra Civil de 1891 en Chile (WIECHMANN, 2000). En otro aspecto, se ha analizado en qué medida Alemania logró expandir su influencia hacia el resto de América Latina a partir de las misiones militares chilenas (FISCHER, 1999; ARANCIBIA, 2002). Finalmente, se ha investigado la influencia prusiana no sólo como organización del sistema 
militar sino también desde el punto de vista formal: marchas, vestimentas etc. (FISCHER, 1999).

Ahora bien, poco se ha atendido a los elementos culturales que estuvieron detrás de la presencia alemana en Chile. Si bien se ha analizado la "prusificación" del ejército chileno, ello más bien ha quedado circunscrito al uso de indumentarias germanas. En este aspecto, falta analizar en qué sentido la noción de Chile como los "prusianos de América del Sur" instaló un debate respecto de la identidad nacional chilena que, de alguna forma, traspasó el ámbito meramente militar.

\section{B. EL DEBATE SOBRE EL EMBRUJAMIENTO ALEMÁN}

La idea de un "embrujamiento alemán" de la sociedad chilena a partir de la presencia de un contingente de profesores en Chile, ha sido analizada en particular atendiendo a una polémica que más bien expresaba pugnas al interior de la élite nacional (NORAMBUENA, 2003). Por otro lado, se ha visto en dicha polémica, liderada por Eduardo de la Barra (18391900), un empeño por combatir la filología alemana que se veía como una fuerte influencia en la formación filológica nacional (VELLEMAN, 2004).

Interesante resulta observar cómo tras las polémicas se encuentran discusiones respecto de la identidad chilena. En un comienzo las críticas de Eduardo de la Barra estuvieron centradas respecto del método usado por los profesores alemanes en Chile, Rudolf Lenz y Federico Hanssen. Sin embargo, ya desde estos trabajos escritos en el exilio en 1894, aparecen elementos de identidades culturales. De allí que de la Barra, algo irónico, fustigue a Hanssen su falta de "oído castellano" aún a pesar de su "paciencia realmente jermánica [sic]" para entender la fonética española (DE LA BARRA, 1897). Aquí no sólo estamos ante una mención "técnica", sino antes bien ante la instalación de estereotipos nacionales. Una vez que de la Barra se enfrasque en el debate al interior del país, desde la prensa, lo anterior se intensificará. De este modo, en primer lugar, define el concepto de "embrujamiento alemán”: “...es una especie de hipnotismo a virtud de la cual los embrujados atropellan por todo [...] y en su afán de enaltecer a 
sus fetiques alemanes, no trepidan en sacrificarles el pasado de Chile [...], negando la verdad histórica" (BARRA, 1899). Esta noción de "embrujamiento" probablemente no fue elegida al azar puesto que históricamente ha sido un tópico para referirse a lo germano, algo que magistralmente recogió el Fausto de Goethe. E incluso, los mismos viajeros latinoamericanos en Alemania, como Benjamín Vicuña Mackenna o Domingo Faustino Sarmiento, en más de un ocasión se refirieron al pueblo alemán como envuelto "en neblinas", "encantado" (SANHUEZA, 2009b). De modo que de la Barra instala un punto de partida poderoso que le permite arremeter en contra de las supuestas virtudes de los profesores alemanes avecindados en Chile.

Otro elemento que es posible notar en las críticas de de la Barra está referido al interés por parte de los filólogos germanos en la lengua mapuche, el habla cotidiana, así como el folklore chileno. En más de un artículo, de la Barra critica el afán evidenciado en Lenz de "restaurar el araucano". El publicista chileno se pregunta: ¿Es necesario recoger "algunos jirones de esa lengua"? ¿Este esfuerzo traerá "luz a nuestra instrucción pública"? (BARRA, 1899). En este punto, de la Barra es muy enfático al negar, en contra de lo que afirma Lenz, la influencia que el mapuche haya tenido en el propio español chileno. De la Barra más bien opta por profundizar el estudio del francés o el inglés, antes que perder el tiempo con idiomas "que casi ni se hablan" (BARRA, 1899).

En otro aspecto, la polémica del embrujamiento alemán dejaba entrever la cuestión respecto de la inserción cultural de Chile en el ámbito europeo. En un sentido, de la Barra critica el hecho de que los chilenos "sacrifiquen el pasado", "negando la verdad histórica" lo que dejaba entrever hasta qué punto la influencia germana atentaba contra la tradición cultural chilena. De lo que se trataba era de combatir el modelo germano, puesto que "Chile había sido educado en el sistema francés" (BARRA, 1899). El propio Valentín Letelier se hizo eco de tales acusaciones criticando a aquellos que se empeñan "en romanizar a la nación, negando la comunión a todo chileno que no se declara romano" (LETELIER, 1940). Al respecto, Letelier afirma que detrás de tal "cruzada antigermánica" se escondía, ni más, ni menos, que una lucha en contra de la "ilustración" del pueblo chileno (LETELIER, 1940). Nuevamente, Letelier pone la discusión en la esfera de la secularización de la sociedad chilena. 


\section{Conclusiones}

Analizar la presencia de intelectuales alemanes en Chile, desde un conjunto de instituciones y círculos, permite estudiar las vías a partir de las cuales el saber se instala. Si se parte del supuesto que la relación intelectual entre un país y otro no corresponde simplemente a "influencias" o "copia de modelos", es posible advertir la complejidad que tales instalaciones implican.

En un sentido, el saber que se busca apropiar no sólo es valorado en sí mismo, en tanto resulta más elaborado o complejo, sino en virtud de su aplicabilidad en un determinado ambiente cultural y simbólico. De esta forma Valentín Letelier, en una época en donde la secularización de la sociedad chilena era objeto de profundos debates, privilegió la formación pedagógica alemana en tanto ésta le permitía quitarle espacio a la educación dominada por órdenes religiosas. El racionalismo asociado con Alemania, su inclinación por la ciencia, podía ser un freno a la visión clerical de la educación. Letelier, en este aspecto, no sólo tomaba la filosofía que estaba tras el sistema de educación germano, sino además sus implicancias políticas. Sólo así era posible romper el círculo de los colegios administrados por la Iglesia, en su mayoría enfocados a las élites, y construir una educación pública y nacional. Letelier ve en Alemania un aliado en tales cometidos.

Por otro lado, no sólo los contenidos en sí mismo se transfieren de un lugar a otro, sino también el capital simbólico desde donde tal saber emerge. En este aspecto, el saber pedagógico germano revelaba la imagen que se poseía de Alemania. Letelier en su informe al gobierno respecto de la educación germana hace hincapié en que medida ésta reflejaba la paciencia infinita y el sentido de experimentación de dicho pueblo. Al respecto, Letelier debió hacerse cargo de la mentada "índole metafísica" del intelecto alemán, destacando cómo ella había sido suplantada por un hacer racional y práctico. En este sentido los cambios ocurridos desde fines del siglo XIX en Alemania, que habían significado el tránsito de la teoría del estado (como en Hegel) a la formación de uno (bajo Federico II), legitimaban el modelo desde un punto de vista que iba más allá de sus meros contenidos y orientaciones. La política del país desde donde se tomaba el saber, desde esta perspectiva, también se introducía al momento de transferir el conocimiento desde un lado del Atlántico al otro. 
En tercer lugar, es posible afirmar que estos movimientos de intelectuales no están exentos de oposiciones y críticas. En un sentido, la instalación de un saber altera el equilibrio local. Lo anterior es particularmente nítido desde la polémica por el embrujamiento alemán en Chile. De lo que se trata no es solamente de una fascinación por un conocimiento desarrollado al otro lado del Rhin, sino también del privilegio que se les daba a los profesores germanos en desmedro de los nacionales. En este punto la defensa de lo propio (lo chileno) se construyó apelando a lo francés. Eduardo de la Barra ve en la presencia germana un atropello a lo que por mucho tiempo había constituido el lugar "natural" de la intelectualidad chilena, en tanto ésta se percibía vinculada con Francia al poseer ambas un pasado cultural común.

La apelación que reivindicaba un vínculo con Francia expresa la posición que los intelectuales chilenos tomaban respecto de su lugar en el concierto de las culturas europeas. La ligazón con el país Galo permitía asegurar un papel de Chile en el marco de aquellas culturas herederas del mundo latino. Esta relación se veía amenazaba con la intromisión de un saber foráneo y ajeno a nuestra propia idiosincrasia. ¿Cómo podía aplicarse un modelo pedagógico de un país cuya base cultural era tan distante de la chilena? Esta interrogante deja entrever que los intelectuales están pensando en la aplicabilidad de un conjunto de ideas y no tan sólo en unos méritos per se.

Finalmente, la relación intelectual entre Chile y Alemania muestra en qué sentido el saber se moviliza. Hans Steffen y Rudolf Lenz no se abocaron tan sólo a sus prácticas pedagógicas: desde la institución (Instituto Pedagógico) construyeron un nicho intelectual. Tal espacio, en gran medida, se legitimaba en la medida en que se apelaba a la procedencia de tales intelectuales. A partir de allí Steffen pudo hacer exploraciones geográficas en la Patagonia Occidental, así como representar al gobierno chileno como experto frente a los litigios de dicho territorio contra Argentina. Lenz, por su parte, desplaza su trabajo desde un saber pedagógico al filológico. Sus investigaciones, enmarcadas en la noción de que los pueblos poseen una suerte de espíritu que los caracteriza, terminaron por elaborar todo un discurso respecto del folklore chileno. Aquí academia e identidad nacional se veían enlazados desde este desplazamiento de saberes.

Todas estas influencias germanas, esta circulación de intelectuales e ideas tuvo un punto de fin. El inicio de la Primera Guerra Mundial en 1914 
detendrá la germanización de Chile. Tras dicho conflicto bélico, si bien las relaciones Chile-Alemania continuarán, difícilmente se pudo alcanzar lo que alguna vez se denominó el "embrujamiento alemán" de la sociedad chilena.

\section{Referências}

BARRA, Eduardo de la. Crítica filológica: examen i refutación de algunas teorías y opiniones del profesor de castellano del Instituto Pedagógico Don Federico Anisen. Santiago: Impr. de la Nueva República, 1897. 1899.

. El embrujamiento Alemán. Santiago: Establecimiento Poligráfico Roma,

BLANCPAIN, Jean-Pierre. Les allemands au Chili:1816-1945. Köln: Bohlau, 1974.

. Los alemanes en Chile: 1816-1945. 4. ed. Santiago: Hachette, 1987.

BOCK, Hans Manfred. Vom Beruf des kulturellen Übersetzens zwischen Deutschland und Frankreich, oder: Verzagen die Mittler. Lendemains, Heft 86/87, p. 8-9, 1997.

BRUCH, Rüdiger et al. Kultur und Kulturwissenschaften um 1900: Krise der Moderne und Glaube an die Wissenschaft. Stuttgart: Franz Steiner Verlag, 1989.

CARRASCO, Germán. Hans Steffen. Pedagogo, geógrafo, explorador, experto en límites. Santiago de Chile: Edición Instituto Geográfico Militar, 2002.

ESPAGNE, Michel. Die Rolle der Mittler im Kulturtransfer. In: LÜSEBRINK, HansJürgen; REICHARDT, R. (Hg.). Kulturtransfer im Epochenumbruch. Frankreich und Deutschland 1770-1815. Leipzig: Leipziger Universitätsverlag, 1997.

GAY, Claudio. Historia física y política de Chile. Paris, 1845.

JAKSIC, Iván. Andrés Bello: la pasión por el orden. Santiago de Chile: Universitaria, 2001.

KREBS, Andrea; TAPIA, Úrsula. Los Alemanes y la Comunidad Chileno-Alemana en la Historia de Chile. Santiago: Liga Chileno-Alemana, 2001.

LATOUR, Bruno. Laboratory Life. The construction of scientific facts. Princeton: Princeton University Press, 1986.

. Science in action. Cambridge: Harvard University Press, 1987.

. Reassembling the social. Oxford: Oxford University Press, 2007. 
LENZ, Rudolf. Chilenische Studien. Phonetische Studien (Marburg in Essen), v. 5,1893 .

LETELIER, Valentín. El Instituto Pedagógico. Santiago de Chile: Publicaciones del Instituto Cultural Germano-Chileno, 1940.

. Las escuelas de Berlín. Informe elevado al Supremo Gobierno por la Legación de Chile en Alemania. Santiago de Chile: Imprenta Nacional, 1885.

LIDENFELDT, David. The Practical Imagination: The German Sciences of State in the Nineteenth Century. Chicago: University of Chicago Press, 1997.

MANN, Wilhel. Der Deutsche Einfluss im chilenischen Erziehungswesen im Allgemeinen. In: Deutsche Arbeit in Chile. Festschrift des deutschen wissenschaftlichen Verein zu Santiago. Santiago de Chile: Imprenta Universitaria, 1910.

NORAMBUENA, Carmen. El embrujamiento alemán, una polémica de fin de siglo. Cuadernos de Humanidades, México, v. 97, Enero-Febrero 2003.

PENNY, Glenn. Objects of culture. Ethnology and ethnography in museums in Imperial Germany. Virginia: University of North Carolina Press, 2002.

PÉREZ ROSALES, Vicente. Memoria sobre la Colonización de la Provincia de Valdivia. Valparaíso: Imprenta del Diario, 1852.

PIETSCHMANN, Horst. Los inicios de la expansión ibérica en el Atlántico y el Imperio alemán. Un aporte historiográfico. In: Revista Complutense de Historia de América, v. 31, p. 9-13, 2005.

POZO, José Miguel. Hans Steffen: maestro, geógrafo y pionero de la Patagonia Occidental. Universum, v. 1, n. 20, 2005.

REVISTA ANALES DE LA UNIVERSIDAD DE CHILE, n. 105, primer trimestre de 1957, Número Especial.

RINKE, Stefan. Eine Pickelhaube macht noch keinen Preussen: preussisch-deutsche Militärberater, Militärethos und Modernisierung in Chile, 1886-1973. In: CARRERAS, Sandra; MAIHOLD, Günther (Ed.). Preussen und Lateinamerika. Im Spannungsfeldt von Kommerz, Macht und Kultur. Münster: Lit, 2004a.

. Begegnung mit dem Yankee. Nordamerikanisierung und soziolkultureller Wandel in Chile (1898-1990). Köln: Böhlau, 2004b.

RÖHL, John, Kaiser, Hof und Staat. Wilhelm II. und die deutsche Politik. Frankfurt am Main: Beck, 2002.

SANHUEZA, Carlos, Chilenos en Alemania y alemanes en Chile. Viaje y nación en el siglo XIX. Santiago de Chile: LOM-DIBAM, 2006a. 
. Noticias desde Berlín. Cartas de Valentín Letelier a Darío Risopatrón Cañas (1883-1885) en coautoría con Isidora Puga. Revista Historia, v. 2, n. 39, p. 557-580, julio-diciembre, $2006 \mathrm{~b}$.

. Desde el otro lado del rio Rhin. Viajeros chilenos en Alemania y representación de la identidad nacional (siglo XIX). In: ETTE, Ottmar; NITSCHACK, Horst. Trans *Chile Cultura-Historia-Itinerarios-Literatura-Educación. Un acercamiento transareal. Madrid, Frankfurt: Vervuert, 2010a.

. He sentido mucho no haber podido penetrar más lejos hacia el sur. Alexander von Humboldt y Chile. Revista Internacional de Estudios Humboldtianos, v. 20, n. XI, p. 135-143, 2010b.

SCHMUCK, Thomas. Im Schatten Humboldts. Poeppig und Humboldt- Ein analytischer Vergleich. In: MORAWETZ, Wilfried; RÖSSER, Martin. Op. cit., p.145-175.

STRAUB, Eberhard, Kaiser Wilhelm II: Die Erfindung des Reiches aus dem Geist der Moderne. Landt, 2008.

VELLEMAN, Barry. Eduardo de la Barra (1839-1900) y el Embrujamiento alemán de la lingüística chilena. In: CORRALES, Cristóbal et al. Nuevas aportaciones a la historiografía lingüística. CONGRESO INTERNACIONAL DE SEHL, 4. Actas ... La Laguna: Arco Libros, 2004.

VIAL, Gonzalo. Historia de Chile (1891-1973), volumen II, Triunfo y decadencia de la oligarquía. Santiago: Editorial Zig-Zag, 1990.

VICUÑA MACKENNA, Benjamín. Le Chili:considéré sous le rapport de son agriculture et de l'émigration européenne, Paris: Bouchard-Huzard, 1855.

. Páginas de mi diario durante tres años de viaje. 1853-1854-1855. Santiago de Chile: Imprenta del Ferrocarril, 1856.

VICUÑA URRUTIA, Manuel. La belle époque chilena: alta sociedad y mujeres de elite en el cambio de siglo. Santiago de Chile: Editorial Sudamericana, 2001.

WIECHMANN, Gerhard, Die preußisch-deutsche Marine in Lateinamerika. 18661914. Eine Studie deutscher Kanonenbootpolitik. Tesis (Doctoral) - Universität Oldenburg, 2000.

Recebido em abril de 2010. Aprovado em abril de 2010. 